\title{
Functional Aspect of Service Sector Development
}

\author{
Valentin Mikhailovich Ryabov \\ Doctor of the economical sciences, director of Togliatti Chemistry-Technological College \\ Elena Valentinovna Ryabova \\ Doctor of the economical sciences, professor Volga Region State University of Service, \\ 445677, Togliatti, Gagarina str., 4
}

Doi:10.5901/mjss.2015.v6n3s2p635

\begin{abstract}
In the context of development of service theory, scientists pay growing attention to need in terminological definition. In this article we examine theoretical models of the term "service", discover the essence of the category "service", renderings of which are characterized by variability. Functional direction and functional peculiarities of services have been defined. Main directions for development of service sector have been detached.
\end{abstract}

Keywords: services, functional direction of services, functional characteristics of services, service sector.

\section{Introduction}

In conditions of market economy many products, created on the base of socially beneficial activities, have acquired commodity form. Consequently, their content and manufacturing and sales technologies have changed, there appeared the factors, aimed at their development. Among such products service is analyzed, which is the product with a set of characteristics, which has some cost and which is sold on the market as a particular product (Demidova, 2007).

Services are considered as certain result of socially beneficial activities, designed as a product or represented by some action. Service should be considered as a form of economic relations, while it is not possible to oppose the essence of service to material form of its appearance. Any service should be provided with a certain material base with the purpose of their execution. There is a difficulty in measuring effect, caused by service rendering (Sosunova, 2006). This difficulty is conditioned by the fact that starting point of service's movement is satisfaction of individual needs, which appears as a attitude basing on labour's profitability, realized in economical form of this service.

In our opinion, knowing of "service" notion must be defined by its functional orientation, where properties of services compose essential part of its functions.

\section{The Main Part}

Generally functions are meant to be certain areas of activities or impact, as well as the means of the activity itself. Also function is considered to be the role of a certain process with regards to the general notion. Since services fulfill two important functions (one is associated with transformation of social nature of human, and the second one is related to transformation of economic system), in modern conditions research logics defined that a way to profound understanding of "service" concept lies through examination of its functional peculiarities. Studying its functions allow accurately define the notion of service. In this connection, special attention is attracted by representation of American scientist T. Hill: "Service is defined as a change of thing or human's condition, being the participant of economic relations, which in its turn is achieved in result of certain conscious actions of other participants of such relations" (Parasuraman, 2009). Such interpretation allows considering service as economical process that consists of a series of intangible actions (means) of cooperation between market's subjects. This phenomenon on the surface of economical processes acts as a relation between service object (receiver) and its executor, where initial point is considered to be individual need of service object, expressed in the form of order, given to the executor. Thus, we define service as economic process, dedicated to some functional changes, which are required by consumer.

Changes that consumer look forward to be provided by service manufacturers, may be of various nature: 
- Changes of condition with respect to consumer goods. Service provider makes some operations with consumer's goods, cleans them, transports them, repair them, and transforms these goods by any other means;

- Changes with respect to private individuals. Service provider transports people, provides them with dwellings, provides them with surgical and therapeutical services, changes their look etc;

- Changes with respect to intellectual and spiritual development of people. Service provider offers educational, consulting and informational services, conducts entertainment programs and renders other similar types of service;

- Changes of economic condition with respect to institutional unit itself. Service provider renders insurance, financial intermediation services, provides warranties and protection.

These changes may be both temporary and constant.

In our opinion, functional peculiarities of service include methods, forms, pribciples and aims for realization of function, which interpret it through "activity" component. They shouldn't be "placed" close to function as something independent from function and use it to form the notion "functional chanracteristics". It is obvious that "function" means activity and work. But this is not any type of activity, but objectially conditioned one. Thus, function's content is related only to objective (material) direction of functional effect of service. Generalizing results of investigations, rdedicated to existing definitions of "service", let us detach some aspects of such rendering (Figure 1).

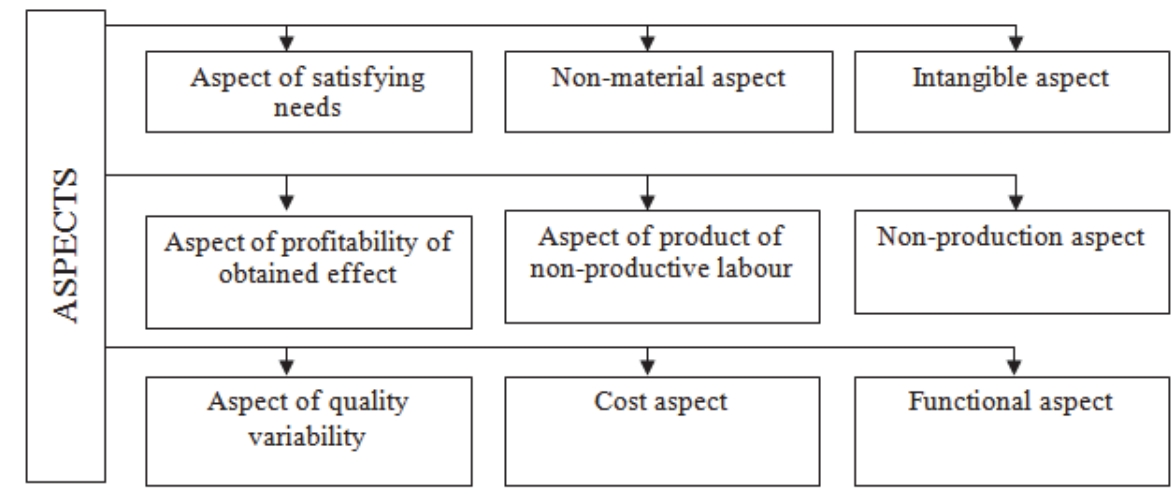

Figure 1. Aspects of rendering "service" notion.

Analyzed aspects of rendering this category allow us defining specific characteristics of service that differ it from other products, created by society. (Figure 2).

Relying on abovementioned multi- dimensionality, let us detach and ground the following service's characteristics

The first characteristic of service - a character and action of productive labour - is, in our opinion, the main and the most specific one. This aspect is explained by the fact that in process of service rendering specific attitude with regards to productive labour appear, which are consumed like activity, i.e. they satisfy certain needs of a person directly in the course of other people's activity, but not the result of such activity, which exists independently (Forecasting and planning in management system of service sector enterprises).

Service's productivity as its characteristic feature is defined by the following. It is well-known that product's characteristic is interesting for potential consumer, provided that he considers it in terms of profitability. 


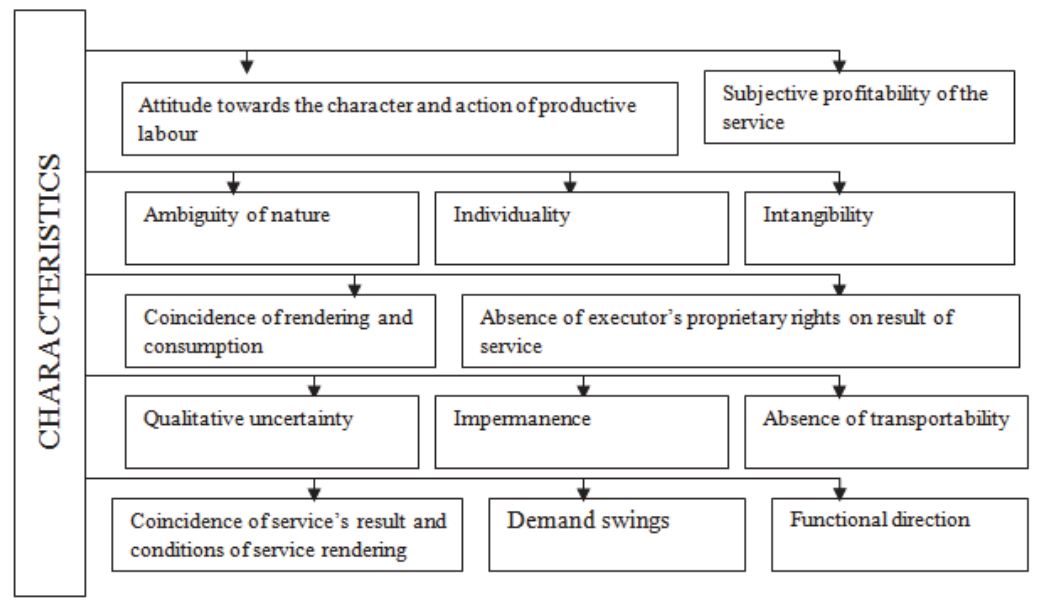

Figure 2. Main characteristics of service as a specific product

And, finally, under functional direction of services we understand the goal of their functional influence on certain object and result. At the same time, objective direction characterizes service's function from the point of view of actual action. Such functional action is represented by specific ties and relations between the subject and the object of functional influence, and reflects means of cooperation that form part of service's function, but not the ones that "provide activity", but "means" of activities. Ability to functionally affect function relations reflect "static starting point" in service functions. Dynamic starting point is expressed in goal-oriented functional activity. Thus, for discovery of content and functions of service, we should examine its new elements -function's aims and goal-oriented activity within the framework of this or that function, which is presented in characteristics of functional direction of service.

An expression "functional direction of service" contains three important characteristics: 1) Direction of functional influence on a certain object; 2) goal-oriented direction of influence within the framework of the function; 3) direction of effect to a certain result.

Scientists believe that service sector is detached as an independent and specific economic sphere, in which dynamics of development is defined by actions of one of the main tendencies in social development, namely anticipation of service sector's growing in comparison with material manufacturing. The reasons of this are considered as influence of economic growth factors on service sector. (Pankratyeva, 2006)

While performing an investigation, we have defined that service sector doesn't have well-defined boundaries, like, for instance, sphere of material production. We think that in most cases "blurring" of boundaries is conditioned by diversity of types and structures and the lack of exact definition of services sector itself.

We believe that since result of any service is directed at satisfaction of consumer by its quality, the service conditions embodied result. The main problem here lies in difficulty of its measurement.

Our understanding of service sector grounds on the range of its specific characteristics with consideration of comparing it with material manufacturing sector.

Understanding of these peculiarities explains the fact that service sector is separated into independent area for investigating means of performance of social labour, based on which special consumer costs are formed, which are consumed by the people not in the form of items, but in the form of services. In this connection service sector is considered by us to be a complex of various types of economical activity with accentuation of goal-oriented and objectoriented directions of functional influence on a certain result.

In our opinion, specific character of service sector is defined by distinctive characteristics of the service itself. Important tendencies of development of service sector in modern conditions was represented by expansive growth of its productive and technological dependency with material manufacture, widening penetration of productive sphere and services in various spheres and types of economic activities, which led to blurring of boundaries among separate sectors. This conclusion is proved by the fact that embodied result and service are interconnected in such new economic complexes as trade, industrial, medical, informational, recreational ones, together satisfying some large social need (Ferrans, 2009).

At the same time, the following specific features of service market are considered: 
1. considerable degree of uncertainty in service sector that places consumer in position, subordinated to service providers, while in most cases their rendering is based on special knowledge and mastery, which are difficult for consumer to estimate;

2. difficulty to compare two offers that compete with regards to joint manufacturing process and consumption of service (for example, consumer may compare only expected and obtained results);

3. activity of service consumer as a main factor in making repetitive purchases of the service;

4. high level of reaction on changes in market conditions, which is explained by impossibility to store and transport the service;

5. subjective content of service providers (as a rule, they are represented by small and medium enterprises of various specializations, which have high mobility and have ample opportunities for speed reaction on changes that occur in the market in comparison with the ones that are more competitive on target service markets);

6. necessity of private contact of service provider and service consumer, which increases the level of requirements to professional qualities, culture and ethics of services' producers and sellers.

When Russian economy entered world market, this process was associated with development of import and export of services, which influenced occurrence of principally new technologies of services' functioning.

Many influences on services was performed by scientific and technical revolution. Services' development was favoured by growing paces of personal computers' production, quick upgrading and cheapening of computer technologies, microelectronics, communication facilities and widening the dimensions of their technical servicing and leasing.

Growth of services' export level and, first of all, such spheres as leasing, engineering, informational servicing etc, explosive development of business sector that favours qualitative transformations of production management, lead to increase of progress pace (Lehtinen, 2006).

In this connection informational technologies, computerization and new communicational media gave base to development of a wide range of services that considerably differ from their classical types, while increasing qualitative indices of servicing. Technical barriers while transmitting remote services reduced, and appearance of technologies opened world market (Strandvik, 2008).

Today we can see development of such services like consultations regarding housekeeping, family budget; there have appeared new forms of public catering service, modern variants of leisure organization. Also, the list of services, directed to management and keeping law enforcement bodies and public authorities has been expanded.

\section{Result}

Therefore, increasing of services' part in economical sphere has also been defined by occurrence of new motivations for their further development. Thus, the most important motivations are:

- Increasing share of private segment in gross domestic product;

- Creation and development of market infrastructure;

- Increase of multiplicative effect's level by increase of demand on the services within the system of service market's infrastructure;

- Low sensitivity of some types of service to cyclical fluctuations;

- Stable dynamics of development of sector and subjective diversification of service sphere;

- Switch from mainly sector administration to mainly territorial administration of service sector with consideration of changing needs of local markets;

- Sharp increase of the role of information support of manufacturing process and services' sales.

The abovementioned allows us making a range of general conclusions.

\section{Conclusions}

Presence of different viewpoints in economical literature regarding the essence of the service, its role and place in national economics, on defining borders of service sector and their classification makes difficult to perceive service as a specific product with some particular characteristics.

We believe that important reason of increasing services' roles in economy lies in the fact that in conditions of development of market economic instruments there have been transformations in manufacturer's orientations in service 
sphere, as currently human's individuality became an important economic feature.

One of the key features of development of service sector in modern conditions is sharp increase of its technological and productive interdependence with material productive sphere, profound interpenetration of production of so-called proprietary product and services into all types of economic activities and economical areas.

\section{References}

Boddewyn, J., 2006. Service multinationals: conceptualization, measurement, and theory. Journal of International Business Studies. Vol. 17. - \# 3. - P. 41-57.

Demidova L., 2007. Service sector in postindustrial economics. World economy and international relations. - No.2. - P. 24-32.

Ferrans, C.E., 2009. Development of a conceptual model of quality of life. Scholarly Inquiry for Nursing Practice. International Journal. \#10. - P. 293-304.

Forecasting and planning in management system of service sector enterprises. - M.: Knorus. $-208 \mathrm{p}$.

Lehtinen, U., 2006. Service quality: A study of quality dimensions, unpublished working paper. Service Management Institute, Finland. P. 82.

Pankratyeva N., 2006. System of statistical indices of service economic sector. - No.4. - P. 16-20.

Parasuraman, A., 2009. Conceptual model of service quality and its implications for future research . Journal of Marketing. - Vol. 49. - P. 41-50.

Sosunova L.A., 2006. Service activity at integrated market. - Samara: Publishing house of Samara State Economic University. - 80 p. Strandvik, T., 2008. Tolerant Zones in Perceived Service Quality. Swedish School of Economics and Business. - Helsinki. - P. 82. Vinorgadova M.V., 2006. Organization and planning of service enterprises. $-2^{\text {nd }}$ edition. - M.: Dashkov and Co. -464 p. 